\title{
APPLICATION OF GEOGRAPHICAL INFORMATION SYSTEMS IN MODELLING OF MILITARY OPERATIONS
}

\section{A. Pincevičius, R. Baušys*, P. Jankauskas}

The General Jonas Žemaitis Military Academy of Lithuania, Vilnius. E-mail: pincev@takas.lt *Vilnius Gediminas Technical Univesity,Vilnius.E-mail: romas@fm.vtu.lt Received 1502 2005, accepted 29082005

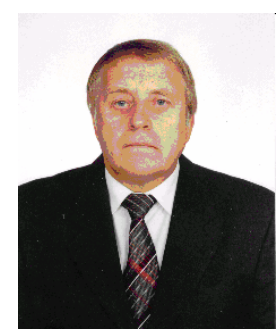

Albertas PINCEVIČIUS, Assoc Prof Dr

Date and place of birth: 1944 in Šeduva, Lithuania.

Education: 1970 - Faculty of Physics of Vilnius University.

Affiliations and functions: 1980 - Doctor.

Research interests: Mathematical Modelling Operation: Modelling of Examinations of Semiconductor Materials, Semiconductor Frames, Problems of Optimisation of Military Operations.

Teaching: Mathematics.

Publications: Author of more than 30 scientific articles; co-author of manual and two textbooks.

Present position: Associate Professor in Department of Applied Sciences at General Jonas Žemaitis Military Academy of Lithuania.

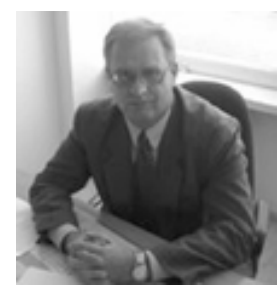

Romualdas BAUŠYS, Prof Dr Habil

Date and place of birth: 1958 in Vilnius, Lithuania.

Education: 1982 - Vilnius Civil Engineering Institute; 1989 - Scientific Degree of Doctor, 2000 - Habil. Doctor, 2001 Professor.

Publications: Author of more than 60 scientific articles.

Present position: Head of Graphical Systems Department at Vilnius Gediminas Technical University.

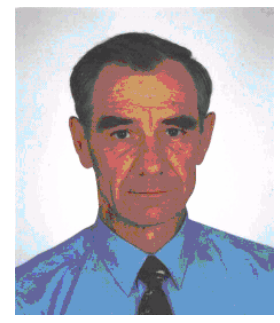

Pranas JANKAUSKAS, Dr

Date and place of birth: 1945 in Ančènai, Molètai District, Lithuania.

Education: 1976 - Engineering Academy of Moscow; 1981 - Adjuncture of Engineering Academy of Moscow.

Affiliations and functions: 1982 - Scientific Degree of Doctor.

Publications: Author of more than 70 scientific articles.

Inventions: 37 inventions.

Awards: 1994 - Third Degree Order of the Gediminas.

Present position: Deputy Chef of General Jonas Žemaitis Lithuanian Military Academy.

\begin{abstract}
The algorithm of the stochastic model of combat is given in article. Random functions describing the basic processes of combat (movement of military personnel, detection of the enemy, firing and its results, etc.) are recorded. Corresponding mathematical expressions and numerical evaluations are given. Application of Geographical Information Systems (GIS) technologies and three-dimensional map in planning battle tactics are discussed.
\end{abstract}

Keywords: modeling, military operations, stochastic models, geographical information systems.

\section{Introduction}

The history of the art of warfare confirms that success on the battlefield is only partially determined by the manpower strength. Very important factors are the choice of appropriate armaments, coordination of combat, effective use of intelligence, features of the relief and meteorological conditions. In a complex way, all of these factors influence the final results of battles - victories, losses, and casualties $[1,10,2]$.

The desire to simulate defensive and offensive operations, to rehearse before a real battle, is understandable. It is known that before attacking the US naval base at Pearl-Harbour in WWII, the Japanese had constructed its mock-up to choose the best model for a surprise attack.

Modelling has become very urgent now; the fight against terrorism is being conducted, and it is necessary to fight an adversary that is well prepared, well armed, and knowledgeable of an area. In this case, the analysis of geographical features, meteorological conditions, and, a multitude of random factors are very important. Each battle, even under apparently identical conditions, will be conducted a different way. To predict the results of a battle or to choose the most suitable way of fighting, it is necessary to repeat the simulated battle with changing random conditions many times. During field training, it is possible to try out only separate elements of a real battle. 
A more complete estimation of the influence of different physical and information a factors, such as the chosen tactics of fighting, efficiency of armaments, and impact of command and control on the course of the battle, can be achieved by using methods of mathematical modelling. The English engineer F. Lanchester offered the first mathematical models of battles in 1916, but a wider interest arose only after WWII. With the increase in the technical capabilities of computers, the sphere of tasks under analysis also expanded.

Geographical Information Systems (GIS) are becoming increasingly indispensable in planning different action plans. Traditional analysis of maps is a sufficiently complex process, calling for high professionalism. Application of GIS technologies considerably simplifies the analysis of terrain when using digital maps. Besides, the application of GIS technologies provides completely new possibilities for researchers to improve the analysis of three-dimensional numerical information [2]. The modelling of operations of military units with a complete estimation of specific terrain substantially increases the accuracy of the modelling, and the results can be used to plan new operations.

\section{Building the mathematical model and the stages of its solution}

The stages of the solution of the task can be determined as $[1,10]$ :

1. Formulation of the task and purposes;

2. Formalization of combat being researched and selection of an adequate mathematical model;

3. Building an algorithm of the model;

4. Creation of the computer program;

5. Discussion and estimation of results obtained. We will begin with the formulation of the task and purposes. Any element of combat has these indispensable parts: combat units, a reconnaissance sub-unit, and command and combat support units (Fig 1). The activities of all of these units need not be described in the model directly. It is possible to analyze only activities of combat and, partially, command units (Fig 1). Activities of reconnaissance and support units can be implied. Due to combat support activities, the number of military personnel, armaments, and ammunition can be increased. Reconnaissance data will be estimated through the activities of command units. Movement of a combat unit to the battle site and the battle itself should be analyzed separately, because their mathematical description will differ greatly.

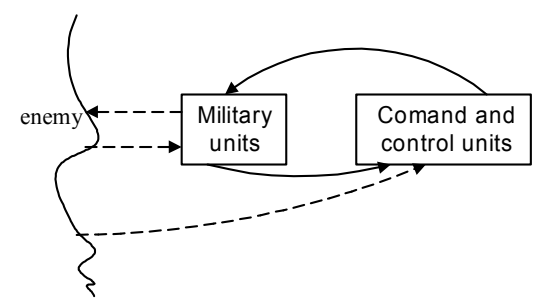

Fig 1. Basic diagrams of combat model: $\longrightarrow$ indicates physical interaction between units, indicates information interaction
Actions of combat units are the most widely researched and described. It is these characteristics of a combat unit that are usually discussed $[1,10,9,6,7]$ :

- ratio of military personnel in defence and offence;

- optimal distribution of military personnel in defence, offence and ambush;

- employment of different armaments and their impact upon the course of the battle;

- mode of employing armaments, order of conducting fire.

Quantitative estimation of tactical elements of a combat unit:

- tactics in offence and defence (beginning of the battle, restriction of enemy movements, employment of different armaments, etc.);

- choice of the positions (visibility zones, utilization of the relief of the terrain, engineering structures);

Quantitative estimation of the efficiency of armaments (impact on the course of the battle):

- optimal technical specifications of armaments in offence and defence (effective range of fire, rounds per minute, armaments scatter parameters, target destruction radius of heavy weapons, etc.);

- $\quad$ composition of the combat kit;

- optimal quantity of ammunition.

It is considerable harder to research the impact of the command and control system on the battle. This system is not determined because the ratio between the entry and exit channels is not completely defined. For example, on the basis of intelligence information received, a "subjective" decision based on personal opinion is made. The influence of the command system has considerably increased recently. Its possibilities have expanded because the scope and speed of the collection of intelligence has increased (satellite and other systems) and information transmission systems are incomparably more accurate (targets, their nature and directions of movement are indicated, movement of friendly forces is adjusted, warning about a possible danger is issued, etc.). It is important to estimate the rationality of the ratio between the prices of armaments and the command and control system.

The study has demonstrated the wide range of tasks under research. The other task is the formalization of combat and selection of an adequate mathematical model.

\section{Stochastic models of combat actions}

Depending on how the description of the process proceeds, mathematical models are divided into two main groups: analytical and stochastic. In the first case, the differential equations describing the operation process (for example the model of F. Lanchester) are written down, and analytical or numerical solutions are provided.

Combat is intricately influenced by a number of random factors, and it is often impossible to describe 
them by using analytical expressions. Statistical models and the Monte-Carlo method are used for this purpose. In case of unknown or very complicated interactions between the objects that are being modelled, this method enables the result of their interaction to be found $[9,5]$.

The actions of military personnel are modelled: movement in the direction of enemy, observation, enemy detection, firing, and destruction of the enemy. Analogous enemy actions are also modelled - that is the detection of the attackers and actions towards their destruction.

Thus two sets of combatants are analysed: $Q=\left(q_{1}, q_{2}, \ldots, q_{n}\right)$ and $\quad U=\left(u_{1}, u_{2}, \ldots, u_{m}\right)$. Military personnel $-q_{i}, u_{j}-$ are the elements of these sets. Each element is defined by a many-dimensional stochastic function - for example, elements $q_{i} \in Q$ by functions $\quad \eta_{i}(t)=\eta_{i}\left(\eta_{i 1}(t), \eta_{i 2}(t), \ldots, \eta_{i r}(t)\right) \quad$ and $u_{i} \in U \quad$ by $\quad \xi_{j}(t)=\xi_{j}\left(\xi_{j 1}(t), \xi_{j 2}(t), \ldots, \xi_{j k}(t)\right)$. The stochastic functions $\eta_{i 1}(t), \eta_{i 2}(t), \ldots, \eta_{i r}(t)$ and $\xi_{j 1}(t), \xi_{j 2}(t), \ldots, \xi_{j k}(t)$ describe the state of each soldier. These random functions describing the course of the battle are further analysed:

$\eta_{i 1}(t), \xi_{j 1}(t)$ - defines the place of a soldier on the battlefield and whether he has been noticed by the enemy; $\eta_{i 2}(t), \xi_{j 2}(t)$ - defines the character of the soldier's actions (examine environment, fire);

$\eta_{i 3}(t), \xi_{j 3}(t)$ - defines the amount of ammunition a soldier possesses;

$\eta_{i 4}(t), \xi_{j 4}(t)$ - defines the soldier's combat capability (whether wounded or not).

After description of the functions $\eta_{i 1}(t), \eta_{i 2}(t)$, $\eta_{i 3}(t), \eta_{i 4}(t)$, the corresponding functions, define actions of the enemy, are written down in a similar way.

Two variants of solution are possible. First variant - we have the map of the terrain and describe the combat in the concrete situation. The second variant - we supposed that the relief has casual character. Thus the received decision has a more general character. In practice both cases are useful and interesting.

Let us assume that a thirty-man-strong platoon fortifies at some elevation and lays an ambush. A reconnaissance patrol determines their approximate location and a hundred-man-strong company receives an order to the clear the road for the movement of the main effort. We will describe a dismounted attack starting at about one kilometre from the enemy. The attacking company in attack covers approximately one kilometre that is military personnel move keeping the distance of $d \approx 8 \div 12$ meters with $v \approx 1 \div 1,6 \mathrm{~m} / \mathrm{s}$ speed. If we analyze the movement every $10 \mathrm{~s}(\Delta t \approx 10 \mathrm{~s})$, it is possible to describe this movement as a transfer to another square (the sides of the square $\approx 10 \times 16 \mathrm{~m}$ ). Let us assume that visibility, relief, and other conditions within this small distance vary only insignificantly. The positions of each soldier are indicating by the indexes of the corresponding square $x_{j}^{i}$, that is the column $1 \leq i \leq 100$ (if the hundred soldiers are attacking, attack takes place width the front zone of $10 \times 100=1000 \mathrm{~m})$ and the line $1 \leq j \leq 50$ (soldier's position within the attack zone $16 m \leq 16 \times 1 \ldots(1 \leq j \leq 50) \ldots 16 \times 50 \leq 800 m$ is indicated). Fig. 2 indicates a fragment of the described attack zone. The position of the fortified enemy is defined by one index - $y^{i}$ (column), because during the battle they will not change their location.
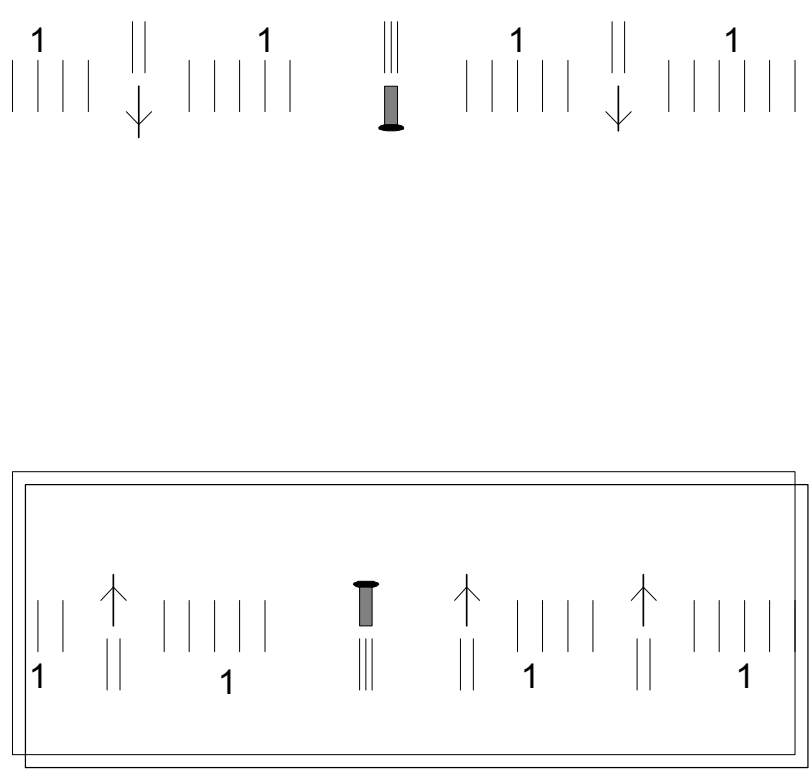

Fig 2. The diagram of the attack. Intervals between military personnel are about $10 \mathrm{~m}$. Two soldiers operate a machine gun

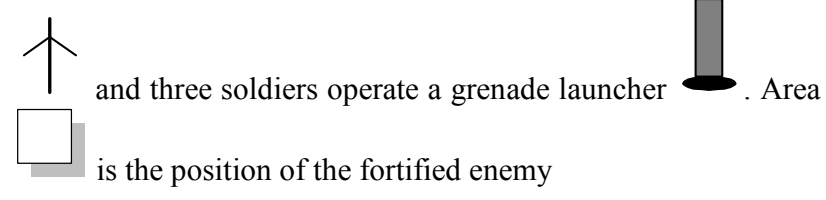

If we have a three-dimensional digital map of the given area, we can make the position more detailed by introducing data on the relief, visibility, and engineering structures (by adjusting the direction, speed, etc. of the movement) into the program.

\section{Application of GIS in the modelling of combat actions}

The application of GIS essentially increases the efficiency of making decisions based on the digital information of battlefield modelling. GIS technologies enable one to easily carry out visibility analyse from a concrete point. Thus probable modelling methods are closely related to relief and urban features of a concrete area. The results of the visibility analysis are submitted in Fig 3. 
It is important to note that it is possible to connect a statistical model of movement and combat to each static element of the system and receive a forecast for the performance of the future military operation depending on concrete features of the terrain and concrete enemy force strength. In this model, using the results of the analysis of visibility, adjustment of target acquisition and hit probability in each analyzed square of the combat is carried out.

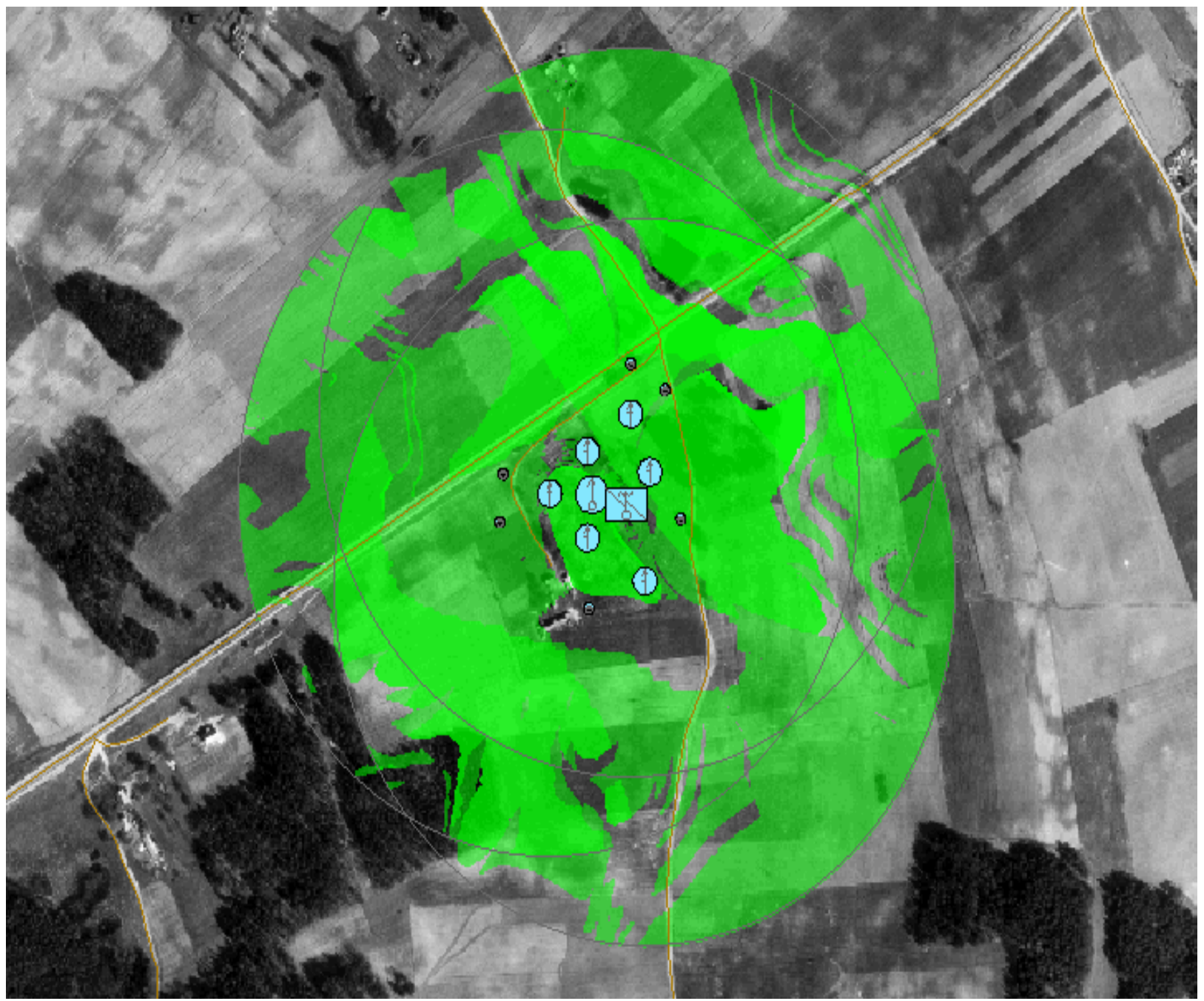

Fig 3. A combined analysis of the visibility for gunners in the angles (radius of visibility $-300 \mathrm{~m}$, sighting point height $-2 \mathrm{~m}$, height of the objects to be observed $-0 \mathrm{~m}$ ) maintaining the scheme of the ambush and graphic basis of the terrain

\section{Modelling of enemy detection}

Building a two-dimensional matrix indicates the probability of detecting soldiers in a certain square. This probability is usually presented by the formula (process of service)

$$
p_{i}^{j}(r)=1-e^{-k \frac{S}{r^{2}} t},
$$

where $S$ is the area of the target, $r$ is its distance from the observer, $t$ is time of observation, and $k$ is coefficient deducted from practical data. The magnitude of $k$ is determined by meteorological conditions, nature of the terrain, etc. The example of dependence of probability of the detection of the target from the distance to it is shown in the Fig 4.

When the first enemy is detected, the pattern of the distribution of others is quickly established and estimated and the battle begins.

Soldiers bearing rifles choose the nearest enemy soldiers or those firing at them as targets. Machines gunners fire at points or targets. Grenade launcher and mortar operators usually destroy group targets or heavy weapons $[3,4,8]$. 


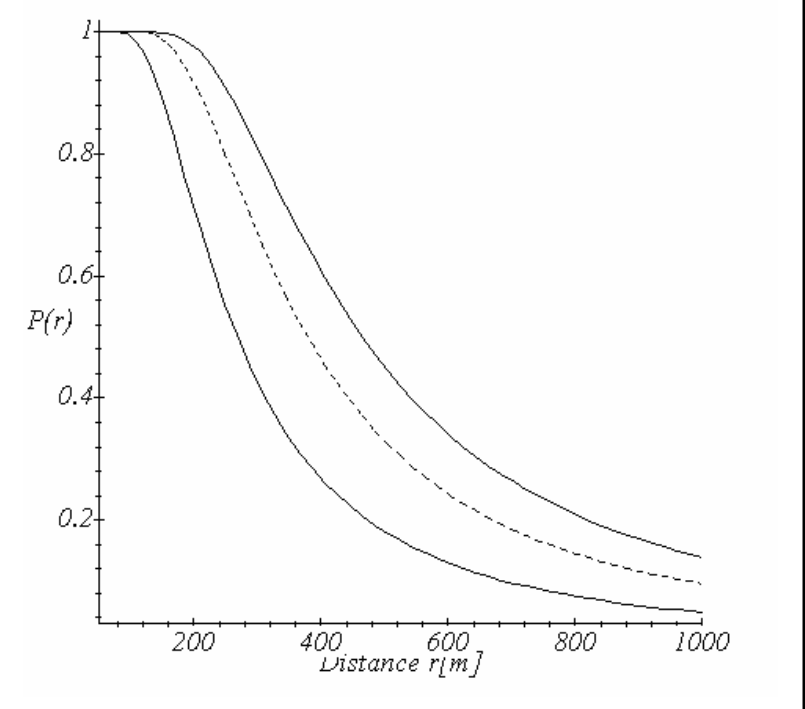

Fig 4. Dependence of probability of the detection of the enemy $P(r)$ from the distance to it. Upper curve corresponds to time of observation $15 s$, dotted $-10 s$, lower $-5 s$

\section{The estimation of the hit probability}

In case of rifle shooting, the probability of hitting the target depends on the distance to the target, type of weapon, accuracy of the soldier, meteorological conditions, and other factors. Deviations are distributed according to the two dimensional normal distribution presented by the formula:

$p_{g}(r)=\frac{1}{\pi \sigma_{x} \sigma_{y}} \int_{x_{1}}^{x_{2} y_{2}} \int_{y_{1}}^{\frac{\left(x-x_{m}\right)^{2}}{2 \sigma_{x}^{2}}} e^{\frac{\left(y-y_{m}\right)^{2}}{2 \sigma_{y}^{2}}} d x d y$

where $\left[x_{1} ; x_{2}\right],\left[y_{1} ; y_{2}\right]$ are intervals that indicate the size of the target, $\left(x_{m} ; y_{m}\right)$ are coordinates of the aiming point (distance from the weapon to the target), and $\sigma_{x}$ and $\sigma_{y}$ are average quadratic deviations, that are determined by weapon design features. The situation when aiming at a soldier from a $400 \mathrm{~m}$ distance looks about like this (Fig 5).

The back sight of the rifle, AK, is at the distance of approximately $80 \mathrm{~mm}$ and is $2 \mathrm{~mm}$ wide. The figure of the soldier $(0,5 \times 1,5 \mathrm{~m})$ from the distance of $400 \mathrm{~m}$ looks $1 \mathrm{~mm}$ wide. The result is considered positive if the moving target is kept within the zone of the sight $(4 \mathrm{~mm})$. In this case, the interval $\left[y_{1}, y_{2}\right]$ in the formula (2) is considered equal to $2 \mathrm{~m}$. The interval $\left[x_{1}, x_{2}\right]$ along the direction of shooting, i.e. along axis $x$ direction, is equal to the range of a point blank shot when the whole trajectory of the bullet does not rise above the target. Fig. 6 presents the computation results. The position of the

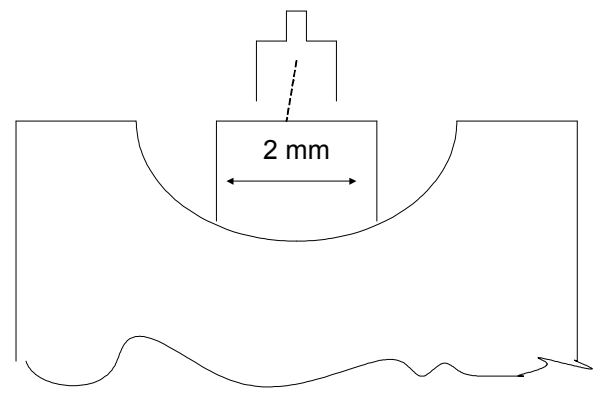

a)

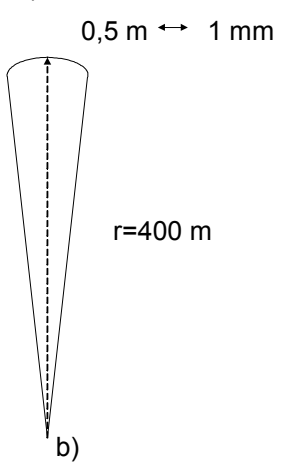

Fig 5. Diagram of aiming from a $400 \mathrm{~m}$ distance

enemy (see Fig. 5) can be chosen at any place of the sight notch zone. Then this zone is divided into 10 equal parts, the hit probability is worked out in each case and afterwards the average of these probabilities is computed. Having done the computations covering eight points (every hundred meters) we generalize them by using the method of least squares.

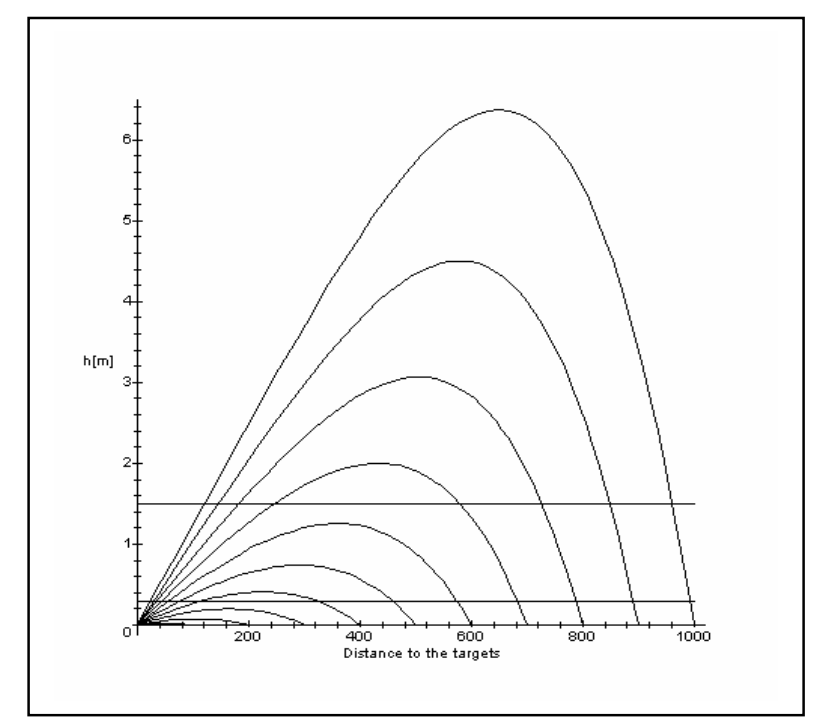

Fig 6. AK 74 bullet trajectories when shooting from $100 \mathrm{~m}$ to $1000 \mathrm{~m}$ distance. The top line corresponds to the shadow height of the attacking soldier $-1.5 \mathrm{~m}-$ and the bottom line to that of the defending soldier $-0.3 \mathrm{~m}$

The dependence of the received hit probability on distance is presented in Fig 7. 


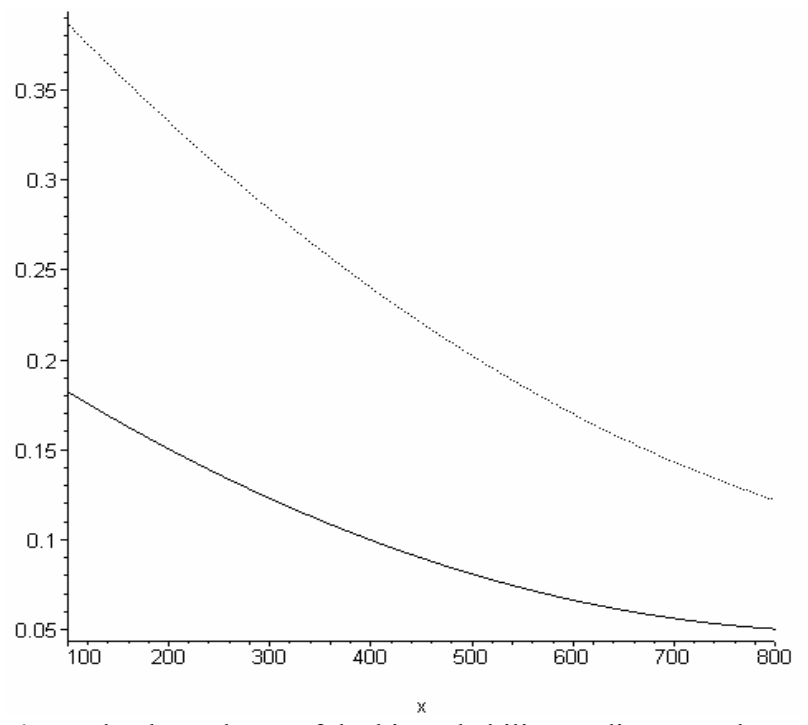

Fig 7. The dependence of the hit probability on distance. The dotted line is the probability for the attacking soldier and the solid line is for the defending soldier

\section{Description of the battle and structure of the algorithm}

The order for the destruction of the enemy fortified in temporary positions has been issued. The strength, location, and armaments of the enemy are approximately known. The actions of a dismounted (combat vehicle would be vulnerable when approaching the enemy), rapid reaction platoon are being modelled. Heretofore, separate assault elements have been analyzed: moving towards the enemy and observation, target acquisition and mathematical description of shooting. Whether a concrete event has taken place is checked this way. For example, if the hit probability $p$ in a concrete case is equal to $0.4(p=0.4)$, the random variable $r$ distributed according to the uniform law, is generated and the condition:

$$
r \leq p
$$

is checked. If the inequality is satisfied, it is considered that the event has taken place, i.e. "the target has been hit". In the opposite case, the event did not happen.

The same model is used to check other events, for example "the enemy has been spotted". Afterwards the results are generalized and the number of casualties or movement to other positions is established. This is repeated until the battle ends: the time for the battle expires, more than half of the personnel are killed, etc. Thus the results of one realization are obtained. Such computations are repeated 100-200 times to find the average of the results (each realization is different because all other random variables are generated) for each computed time moment (point). Fig 8 presents the

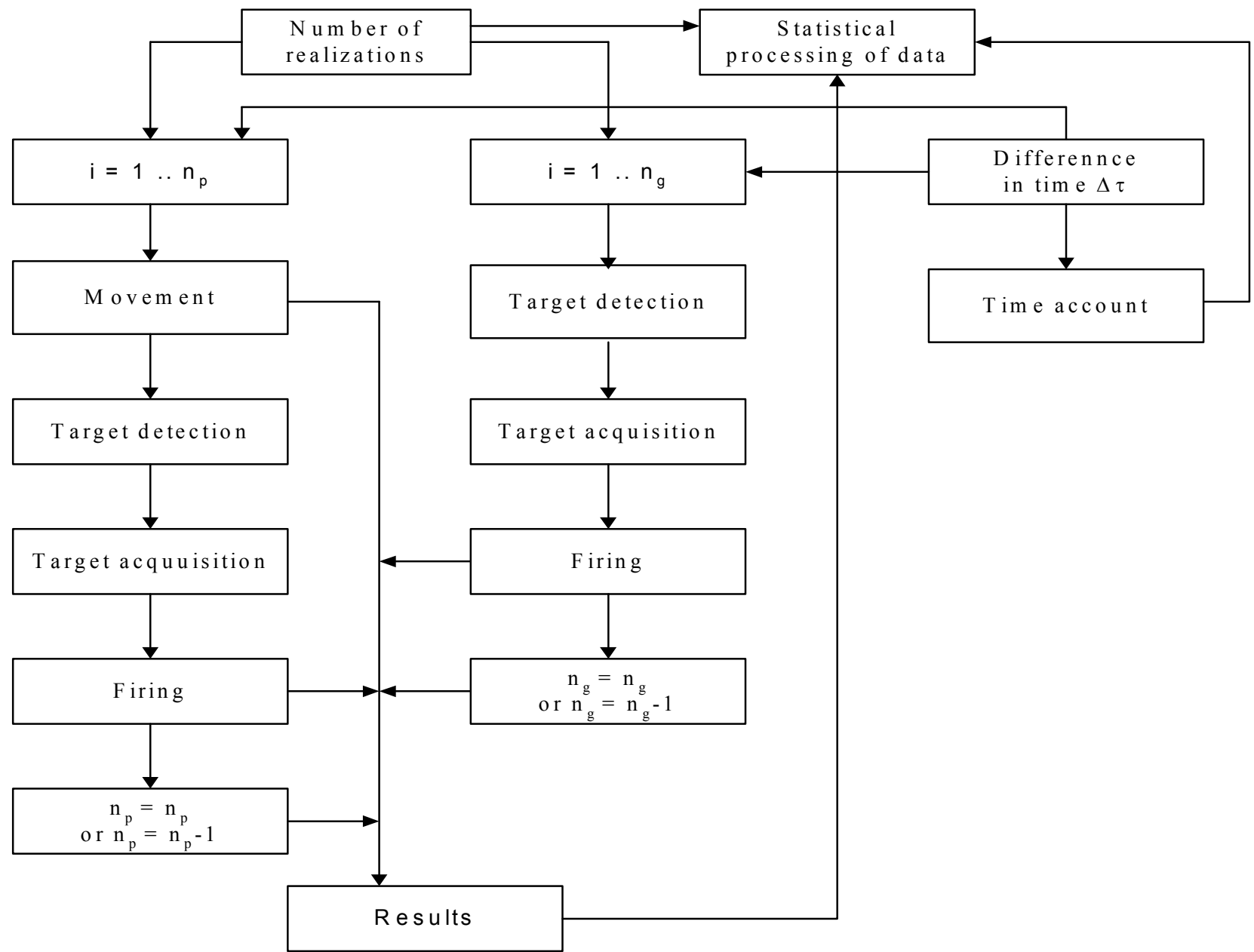

Fig 8. Diagram of the computer program 
diagram of such a program.

The first two columns of the diagram describe the battle process. Two separate cycles describing the actions of the opponents are shown. The third column represents the computer programme for management process.

\section{Conclusions}

The programs developed make it possible:

1. To describe the actions of an individual soldier during combat and analyse the impact of numerous random factors on the course of the battle;

2. To analyze the impact of various weapons on the course of the battle;

3 . To compute the costs of military ammunition and to estimate its quantity necessary to reach the desired result;

4. To estimate the number of soldiers and type of armaments necessary to win the battle, military personnel;

5. To estimate the influence of geographical features, individual tactics of military personnel and movement on the course of the battle;

6. To estimate the influence of command and control units on the course of combat.

\section{References}

1. Coleman C.S. Combat model // Differential equation modes. - New York, 1983. -P. 109131.

2. Crino S.T. Representation of urban operations in military models and simulations // Proc. of the 2001 Winter Simulation Conference, 2001. Website: http://www.wintersim.org

3. Encyclopaedia of modern U.S. military weapons / Ed. T.M. Laur, S.L. Lanso, W.J. Boyne. - New York: Berkley Books, 1995. - 496 p.

4. Jančiauskas I., Venskus A. Balistika. - V.: Lietuvos karo akademija, 1999. - 102 p.

5. Misevičius G., Pincevičius A., Rakauskas R.J. ir kt. Aukštoji matematika. Intensyvių studijų kursas. - V.: TEV, 1999. - 465 p.

6. Pincevičius A., Rakauskas R.J., Misevičius G. et al. The mathematical modelling of counterattack // Liet. matem. rink. - Vilnius, 2001. - 41 t. - P. 542-547.

7. Pincevičius A., Rakauskas R.J., Misevičius G. The numerical simulation of military skills // Ibid. - Vilnius, 2002. - 42 t. - P. 26-33.

8. Purvelis S. Granatsvaidžiai. - Vilnius: LKA, 1997.

9. Венцель Е.С. Исследование операций, Советское радио. - Москва, 1972. - 552 с

10. Ткаченко П.Н. и др. Математические модели боевых действий // Советское радио. - Москва, 1969. - 240 с. 